\title{
Amalgamated gold-nanoalloys with enhanced catalytic activity for the detection of mercury ions $\left(\mathrm{Hg}^{2+}\right)$ in seawater samples
}

\author{
Natasha Logan ${ }^{1}$, Claire McVey ${ }^{1}$, Christopher Elliott ${ }^{1}$, and Cuong $\mathrm{Cao}^{1,2}(\square)$ \\ ${ }^{1}$ Institute for Global Food Security, School of Biological Sciences, Queen's University Belfast, 19 Chlorine Gardens, Belfast, BT9 5DL, UK \\ ${ }^{2}$ Material and Advanced Technologies for Healthcare, Queen's University Belfast, 18-30 Malone Road, Belfast, BT9 5BN, UK
}

(C) The Author(s) 2020

Received: 19 December 2019 / Revised: 20 February 2020 / Accepted: 23 February 2020

\begin{abstract}
Mercury $(\mathrm{Hg})$ is extremely toxic, and continues to cause major threats to aquatic life, human health and the environment. $\mathrm{Hg}^{2+}$ mainly derives from seawater as a product of atmospheric deposition, therefore there is great demand for sensing approaches that can detect $\mathrm{Hg}^{2+}$ in seawater samples. Herein, we demonstrate that the peroxidase-mimicking activity of gold nanoparticles (AuNPs) or so-called nanozymes, can be exploited for the detection of $\mathrm{Hg}^{2+}$ ions in various water samples. In a high electrolyte environment, the catalytic activity for the oxidation of 3,3',5,5'-tetramethylbenzidine (TMB) was significantly diminished due to poor stability of the bare-AuNPs. This activity was reduced by $\sim 73.7 \%$ when the $\mathrm{NaCl}$ concentration was higher than $1.168 \%$, which is much lower than that of seawater $(\sim 3.5 \%)$, thus presenting its unsuitability for detecting $\mathrm{Hg}^{2+}$ in harsh water matrices. To overcome this limitation, AuNPs were first functionalized with oligo-ethylene glycol (OEG), of which their colloidal form presented high stability in $\mathrm{NaCl}$ concentrations up to $20 \%$ and across a wide range of $\mathrm{pHs}$ from 1-14. Interestingly, the catalytic activity of OEG-AuNPs for the oxidation of TMB was strongly suppressed by the coating, but enhanced upon formation of $\mathrm{Au}-\mathrm{Hg}$ amalgamation. This novel finding underlies a straightforward, sensitive, and highly selective detection platform for $\mathrm{Hg}^{2+}$ in water samples. The approach could detect the exposure limit level for $\mathrm{Hg}^{2+}$ in drinking water (i.e., 2 ppb for tap and bottled water) as set by the United States Environmental Protection Agency (EPA) and the World Health Organization (WHO). When $\mathrm{Hg}^{2+}$ was spiked into a $3.5 \%$ saline solution and a coastal seawater certified reference material (CRM), the detection limits were found to be 10 and $13 \mathrm{ppb}$, respectively, which exceed the $\mathrm{Hg}^{2+}$ concentrations commonly found within seawater ( 60-80 ppb). The whole procedure takes less than $45 \mathrm{~min}$ to conduct, providing a highly innovative, rapid and low-cost approach for detecting $\mathrm{Hg}^{2+}$ in complex water matrices.
\end{abstract}

\section{KEYWORDS}

gold nanoparticles, nanozyme, peroxidase-like, mercury detection, water samples, seawater

\section{Introduction}

Mercury $(\mathrm{Hg})$ is a naturally occurring contaminant found in air, soil and water. It is a toxic heavy metal released into the environment via natural (e.g., forest fires, volcanic eruptions) and anthropogenic (e.g., burning fossil fuels, gold mining) sources. The Arctic ice-caps store twice as much $\mathrm{Hg}$ as the atmosphere, ocean and soil combined. Thus, climate change could contribute to the release of up to 15 million tonnes of $\mathrm{Hg}$ into the oceans [1]. Inorganic mercury $\left(\mathrm{Hg}^{2+}\right)$ can transform into neurotoxin methylmercury $(\mathrm{MeHg})$ by bacterial conversion within water bodies. These extremely toxic compounds are highly stable and accumulate within marine systems, causing serious damage to major organs including the brain, nervous system, heart, kidneys and endocrine system when ingested, even at low concentrations [2]. Therefore, it is critical to monitor oceanic $\mathrm{Hg}^{2+}$ levels rapidly, to help prevent the consumption of contaminated seafood.

The United States Environmental Protection Agency (EPA) [3] and the World Health Organization (WHO) [4] have set maximum contaminant levels (MCLs) at $0.002 \mathrm{mg} / \mathrm{L}$ (2 parts per billion, ppb) in drinking water. However, the average level of oceanic mercury is reported to be between $60-80 \mathrm{ppb}$ in shallow waters, where many consumable aquatic animals exist [5]. Methods exploited for the detection of $\mathrm{Hg}^{2+}$ in drinking water and seawater, include inductively coupled plasma mass spectrometry (ICP-MS) [6], energy-dispersive X-ray (EDX) spectroscopy [7] and high-performance liquid chromatography (HPLC) [8], which are limited by complex sample preparation and expensive, bulky instrumentation. Gold nanoparticles (AuNPs) have come to the forefront of sensing technologies due to their inherent plasmonic and catalytic properties. These properties allow for the development of highly robust, sensitive and rapid colorimetric bioanalytical platforms for $\mathrm{Hg}^{2+}$ detection, with the advantages of low cost, simple procedures and reduced need for complex readout instrumentation [9].

Previously, plasmonic AuNPs have been widely exploited for the colorimetric detection of $\mathrm{Hg}^{2+}$ through $\mathrm{T}-\mathrm{Hg}^{2+}-\mathrm{T}$ co-ordination chemistry [10-12] and interactions with molecules such as cysteamine [13], tween-20 [14], papain [15] and thioctic acid [16]. Additionally, AuNPs can mimic the activities of natural enzymes (termed nanozymes), for example horseradish peroxidase (HRP) [17], glucose oxidase [18-20], superoxide dismutase [21] and catalase [22], which have been well documented for 
detecting metal ions, including $\mathrm{Pb}, \mathrm{Co}, \mathrm{K}$ and $\mathrm{Hg}$ [23-25]. However, some of these mimicking behaviours can exhibit relatively low catalytic activity [26]. In the presence of $\mathrm{Hg}^{2+}$ ions, AuNPs demonstrate strong peroxidase-mimicking behaviour for the oxidation of 3,3',5,5'-tetramethybenzidine (TMB) substrate, due to $\mathrm{Au}-\mathrm{Hg}$ amalgamation [27-30]. These important findings have resulted in the development of fluorescence [31] colorimetric [32] and paper-based sensors [33] and the exploitation of catalytically-active nanomaterials including DNA-Ag/Pt nanoclusters [34] and manganese dioxide $\left(\mathrm{MnO}_{2}\right)$ nanorods [35] for the detection of $\mathrm{Hg}^{2+}$ ions.

The size, shape and surface charge of AuNPs can strongly influence their catalytic activities, and these parameters are affected by electrolytic environments [36-39]. In fact, most applications for $\mathrm{Hg}^{2+}$ ion detection focus on low-electrolyte matrices including drinking water [40] and river water [41]. Limited applications to high salinity matrices (i.e., seawater) may be attributed to the nanomaterials suffering from stability issues in complex biological systems and reduced sensitivity, as a result of AuNP aggregation [42]. To improve stability, AuNPs are commonly modified with synthetic polymers including, polyethylene glycol (PEG) [43, 44] and oligoethylene glycol (OEG) $[45,46]$.

Herein, we demonstrate the reduced peroxidase-mimicking activity of aggregated bare-AuNPs, regardless of the formation of $\mathrm{Au}-\mathrm{Hg}$ nanoalloys, which have previously demonstrated strong peroxidase-mimicking activity [30]. To overcome the detrimental effects to catalytic activity and improve applications to high electrolyte mediums, the AuNPs were functionalised with oligo-ethylene glycol (OEG). The obtained OEGfunctionalised AuNPs (OEG-AuNPs) not only show excellent stability in high salt concentrations and in different $\mathrm{pHs}$, but also suppressed catalytic activity. Interestingly, in the presence of $\mathrm{Hg}^{2+}$ ions the catalytic activity of the OEG-AuNPs is recovered, resulting in a highly selective and sensitive assay for the detection of $\mathrm{Hg}^{2+}$ in complex water samples. The approach takes less than 45 min to conduct, requires common reagents to perform and can be conducted at room temperature, thus highlighting its low-cost and practical procedures. In addition, the colorimetric response can be analysed without the need for complex equipment, therefore can improve the on-site analysis of complex seawater samples, where $\mathrm{Hg}^{2+}$ contamination is most abundant. These features of the developed approach are advantageous as compared to traditional methods.

\section{Experimental section}

\subsection{Chemicals and reagents}

Sodium citrate tribasic dehydrate ( $\mathrm{HOC}(\mathrm{COONa})$ $\left.\left(\mathrm{CH}_{2} \mathrm{COONa}\right)_{2} \cdot \mathrm{aq}\right)$, gold (III) chloride trihydrate $\left(\mathrm{HAuCl}_{4} \cdot 3 \mathrm{H}_{2} \mathrm{O}\right.$, $99.9 \%)$, mercury (II) perchlorate hydrate $\left(\mathrm{Hg}\left(\mathrm{ClO}_{4}\right)_{2} \cdot x \mathrm{H}_{2} \mathrm{O}\right.$, 99.998\%), O-(2-Mercaptoethyl)-O'-methyl-hexa(ethylene glycol) $\left(\mathrm{C}_{15} \mathrm{H}_{32} \mathrm{O}_{7} \mathrm{~S}, 95 \%\right)$, sodium chloride $(\mathrm{NaCl})$, hydrochloric acid ( $\mathrm{HCl})$, sodium hydroxide $(\mathrm{NaOH}), 3,3$ ',5,5'-tetramethybenzidine (TMB), hydrogen peroxide $\left(\mathrm{H}_{2} \mathrm{O}_{2}\right)$, nitric acid $\left(\mathrm{HNO}_{3}\right)$, sodium borohydride $\left(\mathrm{NaBH}_{4}\right)$, phosphate buffered saline (PBS), acetic acid $\left(\mathrm{CH}_{3} \mathrm{COOH}\right)$ and sodium acetate $\left(\mathrm{CH}_{3} \mathrm{COONa}\right)$ were all purchased from Sigma Aldrich (UK). TEM carbon coated, copper grids were purchased from Agar Scientific (UK). Syringe filters $(0.22 \mu \mathrm{m})$ were purchased from Merk Millipore (Germany). Natural mineral water (Acqua Panna) was purchased from a local food establishment (Spar Store, Belfast, UK). Coastal seawater $\mathrm{Hg}^{2+}$ certified reference material (CRM) was purchased from LGC Standards (UK).

\subsection{Analysis instrumentation}

Ultraviolet-visible spectroscopy (UV-vis) measurements were performed using a Cary 60 spectrophotometer (Agilent Technologies, USA). Absorbance measurements were carried out using a Tecan Safire ${ }^{2}$ plate reader (Tecan, Switzerland). AuNP size and zeta-potential measurements were carried out using a Zetasizer NanoZS (Malvern, UK). Transmission electron microscopy (TEM) measurements were conducted on a Joel JEM 1400 Plus Transmission Electron Microscope, operated at $100 \mathrm{kV}$. Fourier-transform infrared (FTIR) spectroscopy measurements were conducted on a Nicolet iS5 FTIR Spectrometer (ThermoFisher Scientific, UK). Elemental mapping, high-angle annular dark-field-scanning transmission electron microscopy (HAADF-STEM) and energy-dispersive X-ray spectroscopy (EDS) were carried out using a TALOS FEI High Resolution Transmission Electron Microscope (HRTEM), operated at $200 \mathrm{kV}$ (ThermoFisher, UK).

\subsection{Synthesis and functionalisation of gold nano- particles (AuNPs) with oligo-ethylene glycol (OEG)}

AuNPs are synthesised using the Turkevich method, with minor adjustments [47]. Briefly, $1 \mathrm{mM} \mathrm{HAuCl}_{4}$ was dissolved in 100 $\mathrm{mL}$ of deionised water $\left(\mathrm{dH}_{2} \mathrm{O}\right)$ and heated until rapidly boiling. Upon reflux $10 \mathrm{~mL}$ of $1 \%$ sodium citrate was quickly added to the boiling solution, under vigorous stirring. The solution was removed from the heat upon a colour change from yellow to wine-red, which indicates the citrate reduction of gold ions. For functionalisation, typically $0.5 \mathrm{mM}$ OEG was incubated with $2 \mathrm{~mL}$ of as-prepared AuNPs overnight at room temperature. The particles were centrifuged at 16,100 rcf twice for $20 \mathrm{~min}$, to remove unbound OEG. The pellet containing OEG-particles was re-suspended in $\mathrm{dH}_{2} \mathrm{O}$ and stored at $4{ }^{\circ} \mathrm{C}$ for further use.

\subsection{Analysis of AuNP catalytic activity in the presence of different $\mathrm{NaCl}$ concentrations}

In a typical experiment, AuNPs were pre-treated with various concentrations of $\mathrm{NaCl}(0-0.5 \mathrm{M})$, and $1.25 \mathrm{mM} \mathrm{TMB} / 2 \%$ $\mathrm{H}_{2} \mathrm{O}_{2}$ solutions were added to the mixture. All samples were incubated at room temperature for $10 \mathrm{~min}$, followed by absorption measurements, kinetic analysis and dynamic light scattering (DLS) analysis.

\subsection{Catalytic activity of bare-AuNPs and OEG- functionalised AuNPs in the presence of $\mathrm{Hg}^{2+}$ ions}

Prior to analysis, a stock solution of $\mathrm{Hg}^{2+}$ was prepared at $20,000 \mathrm{ppm}$ in $0.02 \mathrm{M} \mathrm{HNO}_{3}$ (stored at $4{ }^{\circ} \mathrm{C}$ ). In a typical experiment, $85 \mu \mathrm{L}$ of $\mathrm{Hg}^{2+}$ ions $(0-1 \mathrm{ppm})$ were transferred to a 96-well microtitre plate. Bare-AuNPs $\left(15 \mu \mathrm{L}, 1.7 \times 10^{-9} \mathrm{M}\right)$ were subsequently added and incubated for $2 \mathrm{~min}$ at room temperature to allow amalgamation. Finally, $1.25 \mathrm{mM} \mathrm{TMB} / 6 \%$ $\mathrm{H}_{2} \mathrm{O}_{2}$ was added and incubated for a further $10 \mathrm{~min}$ at room temperature. Similarly, the $\mathrm{Hg}^{2+}$ concentrations (0-1 ppm) were spiked into a saline solution (containing $3.5 \% \mathrm{NaCl}$, pre-filtered using a $0.22 \mu \mathrm{m}$ syringe filter to remove impurities) and the previous procedure repeated to analyse the performance of $\mathrm{Au}-\mathrm{Hg}$ amalgam in high electrolyte conditions. For OEG-AuNP, various concentrations of $\mathrm{Hg}^{2+}$ were prepared in $\mathrm{dH}_{2} \mathrm{O}$ and transferred to a microtitre plate $(150 \mu \mathrm{L})$. The OEG-AuNP conjugate was subsequently added $(0.5 \mu \mathrm{L}$, as-prepared), followed immediately by $0.2 \mathrm{M} \mathrm{NaBH}_{4}$ and incubated at room temperature for $5 \mathrm{~min}$. Finally, $1.25 \mathrm{mM} \mathrm{TMB} / 6 \% \mathrm{H}_{2} \mathrm{O}_{2}$ was added and incubated for a further $10 \mathrm{~min}$ at room temperature. Prior to analysis, the plate was sealed and sonicated for $3 \mathrm{~min}$ 
to remove any bubbles formed as a result of hydrogen released from $\mathrm{NaBH}_{4}$.

\subsection{Detection of $\mathrm{Hg}^{2+}$ ions in different water samples using OEG-AuNPs}

Bottled and tap water were collected from a local establishment and the laboratory, respectively and filtered using a $0.22 \mu \mathrm{m}$ syringe filter to remove any particulate impurities. A 3.5\% saline solution to simulate the salinity of seawater was prepared as mentioned previously. After filtration the $3.5 \%$ saline solution was used to prepare spiked water samples with $\mathrm{Hg}^{2+}$ concentrations in the range of $0-1 \mathrm{ppm}$ and the assay was repeated. Additionally, the same $\mathrm{Hg}^{2+}$ concentrations were also spiked into a certified coastal seawater reference material (CRM) to validate the applicability of the approach.

\section{Results and discussion}

\subsection{Gold nanoparticles (AuNPs) exhibit a strong peroxidase-like activity for the oxidation of TMB substrate}

AuNPs (average diameter $\sim 13-20 \mathrm{~nm}$ ) were synthesised using the sodium citrate reduction of $\mathrm{HAuCl}_{4}$, with minor adjustments [47]. The particles synthesised by this method exhibit a net negative charge $(\zeta=-48.1 \mathrm{mV})$, and a deep ruby-red colour (Fig. 1(a), cuvette far left) showing a UV-vis absorbance band at $519 \mathrm{~nm}$ (Fig. 1(b), red line). The concentration of the synthesised AuNPs $\left(\mathrm{OD}_{\Theta 520 \mathrm{~nm}}=1.0\right)$ was $5 \times 10^{-9} \mathrm{M}$, as calculated by their mean diameter and corresponding extinction coefficient value, as described previously [48]. Figure 1 indicates that after $10 \mathrm{~min}$ in the presence of $2 \% \mathrm{H}_{2} \mathrm{O}_{2}$, TMB was not oxidized unless AuNPs were present. With the addition of AuNPs to $\mathrm{TMB} / 2 \% \mathrm{H}_{2} \mathrm{O}_{2}$, the rate of the oxidation reaction is greatly enhanced, which can be observed at wavelengths 370 and $650 \mathrm{~nm}$ (Fig. 1(b), blue line). Additionally, kinetic analysis can also confirm the increased reaction rate over a $10 \mathrm{~min}$ incubation in the presence of AuNPs, at a fixed wavelength of $370 \mathrm{~nm}$ (Fig. 1(c), blue triangles). Due to the overlapping of plasmonic peak from AuNP aggregation $(\sim 650 \mathrm{~nm})$ with the second peak from oxidised TMB (oxTMB), the most prominent peak at $370 \mathrm{~nm}$ was selected for analysis [17]. From these results, it is evident that the presence of AuNPs notably enhances the rate of TMB oxidation therefore, confirming the strong peroxidase-mimicking activity of bare-AuNPs.

The catalytic mechanism of the negatively charged AuNPs can be explained by the decomposition of $\mathrm{H}_{2} \mathrm{O}_{2}$. During the oxidation of TMB, TMB acts as a hydrogen donor whilst $\mathrm{H}_{2} \mathrm{O}_{2}$ acts as the recipient of the electron, to split $\mathrm{H}_{2} \mathrm{O}_{2}$ into $\mathrm{H}_{2} \mathrm{O}$ and $\mathrm{O}_{2}$. Citrate-capped AuNPs speed up this process as they possess an extra electron from gold, which can be readily transferred to the adsorbed $\mathrm{O}_{2}$ on the surface of the AuNPs, weakening the $\mathrm{O}-\mathrm{O}$ bond. This leads to $\mathrm{H}_{2} \mathrm{O}_{2}$ being split into double hydroxyl radicals which can be stabilised by the AuNP, via a partial electron exchange interaction. The newly formed hydroxyl radicals oxidise TMB, thus contributing to the nanozymes peroxidase-like activity [49], producing a blue coloured product with two very distinct absorption peaks at 370 and $650 \mathrm{~nm}$. Furthermore, TMB substrate is positively charged and has strong affinity to the negatively charged AuNP, thus electrostatic interactions facilitate the reaction further [50].

\subsection{The peroxidase-like activity of AuNPs is inversely proportional to the particle aggregation state}

As reported in the scientific literature, the catalytic activity is inversely proportional to the nanoparticle size. Therefore, it is rational to hypothesise that nanoparticle aggregation would also strongly influence this property. To investigate the hypothesis, AuNPs were treated with different $\mathrm{NaCl}$ concentrations ranging from zero to $0.5 \mathrm{M}(\sim 0-2.92 \%)$ to induce particle aggregation. To confirm $\mathrm{NaCl}$-induced aggregation, TEM was conducted on AuNPs in the absence and presence of $0.5 \mathrm{M} \mathrm{NaCl}$ (Figs. S1(a) and S1(b) in the Electronic Supplementary Material (ESM), respectively). Figure 2(a) (top) illustrates the colour change of the AuNP solution from red to blue. The UV-vis analysis data (Fig. S2 in the ESM) indicates that the LSPR peak of the AuNPs shifts to a longer wavelength, with partial and complete aggregation occurring after the addition of $0.06 \mathrm{M} \mathrm{NaCl}$ $(\sim 0.35 \%)$ and $0.1 \mathrm{M} \mathrm{NaCl}(\sim 0.58 \%)$, respectively. To examine the effect of AuNP aggregation on the peroxidase-like activity,

(a)
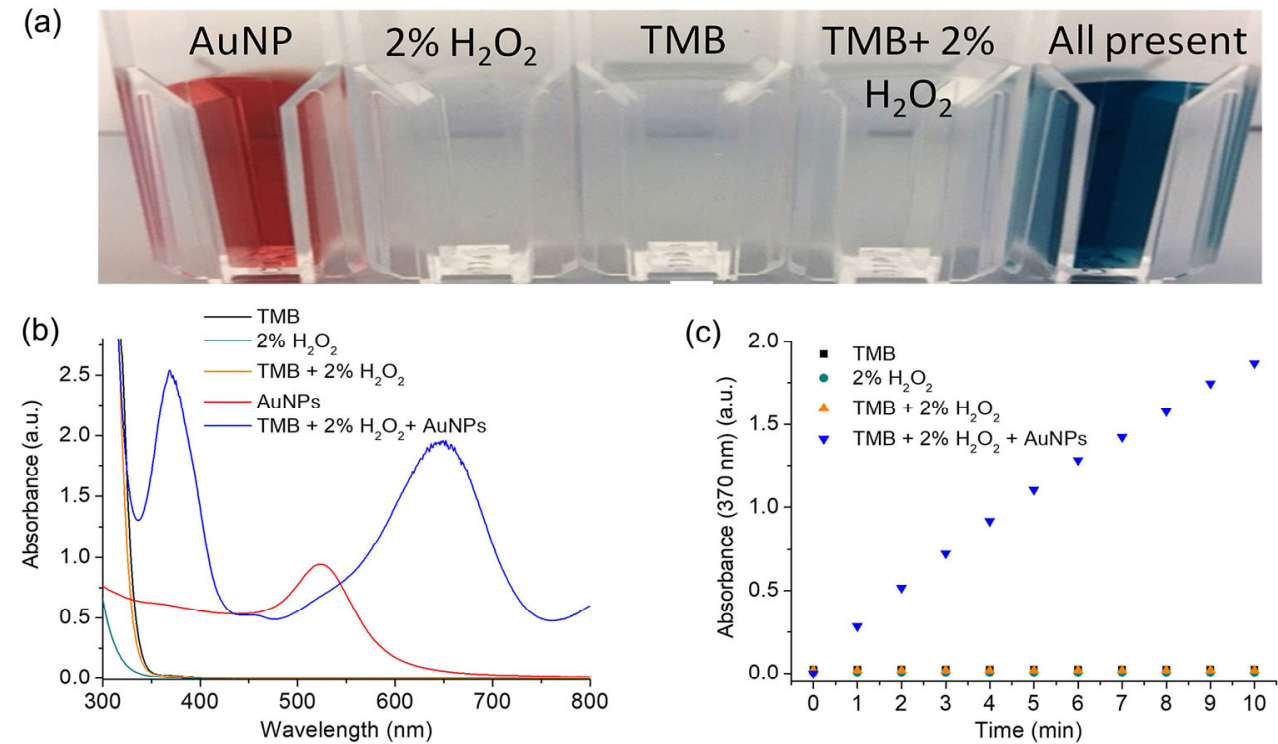

Figure 1 Evidence of bare-AuNPs exhibiting a strong peroxidase-like activity. (a) A colour photograph of colloidal AuNP solution $\left(\mathrm{OD}_{\varrho} 520 \mathrm{~nm}=1.0\right), 2 \%$ $\mathrm{H}_{2} \mathrm{O}_{2}$ alone, TMB (1.25 mM) alone, $1.25 \mathrm{mM} \mathrm{TMB}$ and $2 \% \mathrm{H}_{2} \mathrm{O}_{2}$ mixture, $1.25 \mathrm{mM} \mathrm{TMB} / 2 \% \mathrm{H}_{2} \mathrm{O}_{2}$ in the presence of AuNPs. All solutions were kept at room temperature, and the image was taken after $10 \mathrm{~min}$. (b) Corresponding UV-vis spectra. (c) Kinetic analysis of the solutions after $10 \mathrm{~min}$ at a fixed wavelength of $370 \mathrm{~nm}$. 


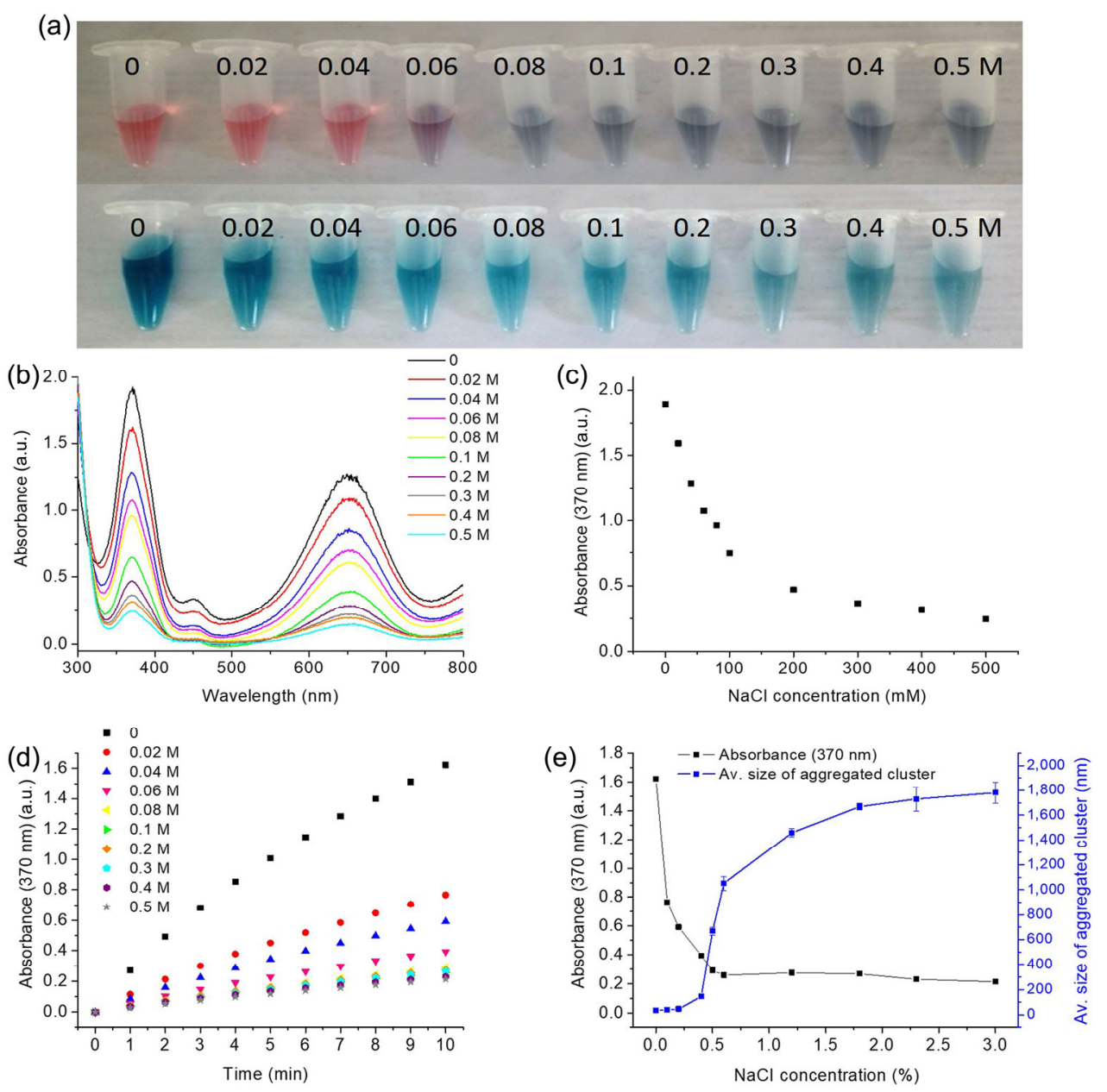

Figure 2 The peroxidase-like activity of colloidal AuNPs $\left(\mathrm{OD}_{\Theta_{520} \mathrm{~nm}}=1.0\right)$ in the presence of $\mathrm{NaCl}$. (a) (top) Colour photograph of AuNP aggregation with different concentrations of $\mathrm{NaCl}$. (below) colour photograph of peroxidase-like activity of the corresponding AuNPs after aggregation and addition of $1.25 \mathrm{mM} \mathrm{TMB} / 2 \% \mathrm{H}_{2} \mathrm{O}_{2}$. (b) UV-vis analysis demonstrating peaks at 370 and $650 \mathrm{~nm}$ indicative of oxTMB product. (c) Absorbance at $370 \mathrm{~nm}$ as a function of $\mathrm{NaCl}$ concentration. (d) Kinetic analysis over a $10 \mathrm{~min}$ incubation illustrating the peroxidase-like activity of AuNPs after NaCl-induced aggregation. (e) Correlation between the average size of AuNP clusters Vs. the catalytic activity (absorbance at $370 \mathrm{~nm}$ produced by oxTMB), affected by varying the $\mathrm{NaCl}$ concentration and measured using DLS. Standard deviation $(\sigma)$ was calculated from triplicate samples $(n=3)$.

$1.25 \mathrm{mM}$ TMB and $2 \% \mathrm{H}_{2} \mathrm{O}_{2}$ was introduced to the AuNPs pre-treated with different $\mathrm{NaCl}$ concentrations. Figures 2(a) (below) and 2(b) demonstrate as the concentration of $\mathrm{NaCl}$ increases there is a decline in the peroxidase-like activity, witnessed by a reduction in peak absorbance at both 370 and $650 \mathrm{~nm}$. Figure 2(c) also highlights the correlation between $\mathrm{NaCl}$ concentration and reduced peroxidase-like activity at a fixed wavelength of $370 \mathrm{~nm}$. The AuNPs witness 73.7\% decrease in catalytic efficiency when faced with $\mathrm{NaCl}$ concentrations above $1.168 \%(\sim 0.2 \mathrm{M})$. Therefore, these results can confirm that the peroxidase-like activity is strongly dependent on the particle aggregation state. Additionally, it was important to confirm that this reduction in catalytic activity was attributed to particle aggregation and not by the addition of $\mathrm{NaCl}$. The same samples were centrifuged to remove $\mathrm{NaCl}$ in the surrounding medium, and the catalytic activity of the pellet (Fig. S3(a) in the ESM) and supernatant (Fig. S3(b) in the ESM) was analysed. The results confirm that in the absence of $\mathrm{NaCl}$ the catalytic activity of the aggregated nanoparticles remained the same and the supernatant containing $\mathrm{NaCl}$ did not exhibit any peroxidase-like activity. To further investigate the reduction in reaction rate over time, kinetic analysis was conducted. Figure 2(d) further illustrates the depletion in reaction rate over a time period of $10 \mathrm{~min}$, with increasing $\mathrm{NaCl}$ concentrations. Figure 2(e) highlights the average hydrodynamic size of the aggregated clusters gathered from DLS, compared with the absorbance values at $370 \mathrm{~nm}$ in the presence of $\mathrm{NaCl}$. These results confirm that when aggregation is induced with $\mathrm{NaCl}$ the size of the particles or particle clusters dramatically increases (blue line), thus having a negative impact on the catalytic activity of the nanozyme (black line).

3.3 When the AuNPs are aggregated, their catalytic activity is suppressed regardless of the presence of $\mathrm{Hg}^{2+}$ ions

Figure 3(a) indicates that the catalytic activity of the bare-AuNP was significantly enhanced by the presence of $\mathrm{Hg}^{2+}$ ions at $1 \mathrm{ppm}$ (cyan line) after $10 \mathrm{~min}$ incubation with $1.25 \mathrm{mM}$ TMB and $6 \% \mathrm{H}_{2} \mathrm{O}_{2}$ (working concentration). Similarly, the kinetic analysis confirms the enhancement of AuNP catalytic activity in the presence of $\mathrm{Hg}^{2+}$ ions over a $10 \mathrm{~min}$ incubation period (Fig. 3(b), cyan triangles). To investigate further steady-state kinetics were carried out to investigate the peroxidase-like activity of $\mathrm{Au}-\mathrm{Hg}$ amalgam in comparison to the bare-nanozyme (Fig. S4(a) in the ESM). The results suggest that the maximum reaction velocity of AuNPs is greatly reduced in the absence of $\mathrm{Hg}^{2+}\left(V_{\max }=2.34 \times 10^{-6} \mathrm{M} \cdot \mathrm{min}^{-1}\right)$. However, AuNPs continue to catalyse the oxidation reaction in the presence of $\mathrm{Hg}^{2+}(1 \mathrm{ppm})$ at a much faster rate, due to the formation of $\mathrm{Au}-\mathrm{Hg}$ amalgam $\left(V_{\max }=7.70 \times 10^{-6} \mathrm{M} \cdot \mathrm{min}^{-1}\right)$ and the catalytic efficiency of the 

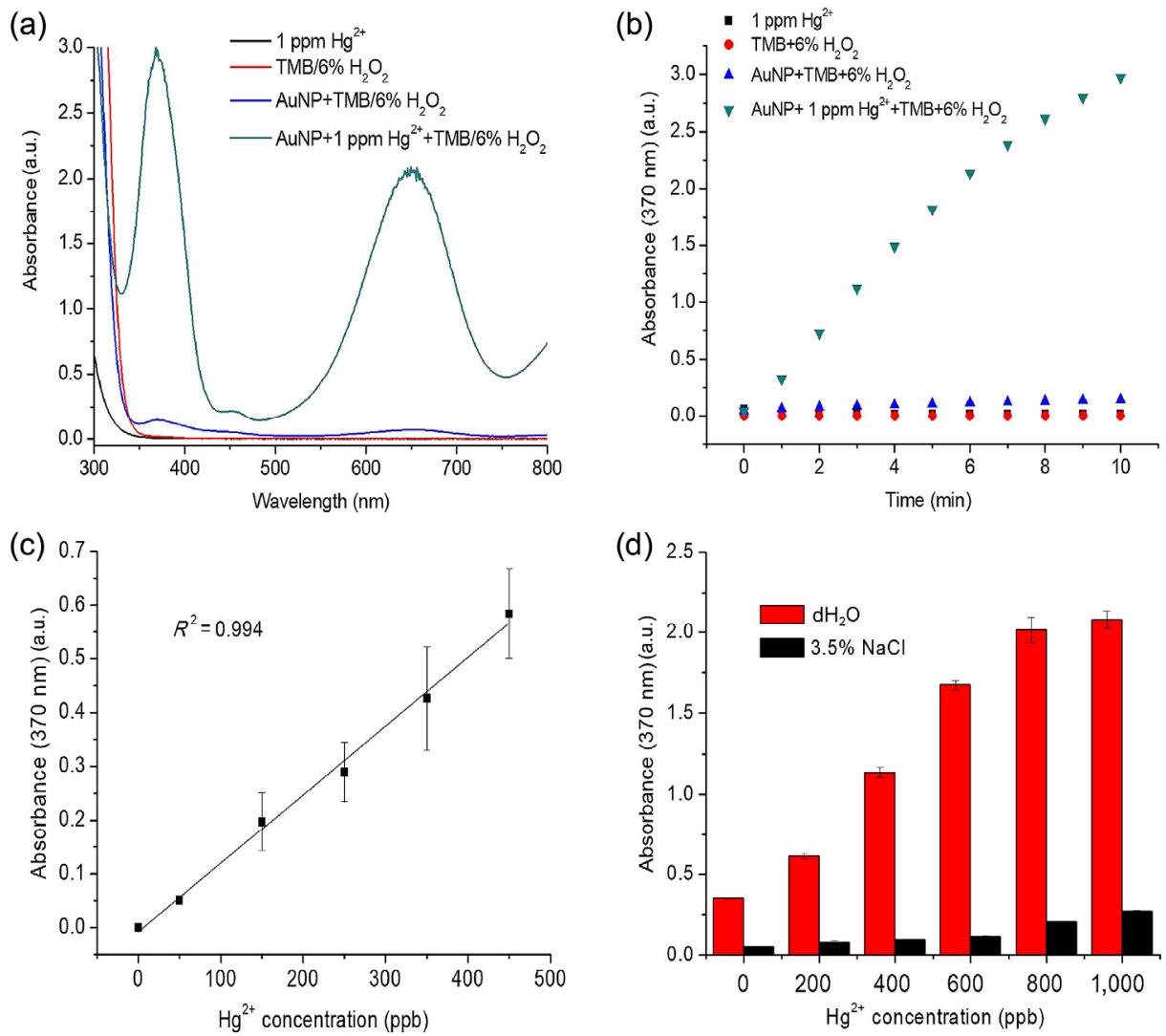

Figure 3 The catalytic activity of bare nanozyme $\left(0.85 \times 10^{-9} \mathrm{M}\right)$ in the presence of $\mathrm{Hg}^{2+}$ ions. (a) Full wavelength spectra of bare-AuNPs in the absence (blue line) and presence of $\mathrm{Hg}^{2+}$ ions (cyan line) after incubation with $1.25 \mathrm{mM} \mathrm{TMB}$ and $6 \% \mathrm{H}_{2} \mathrm{O}_{2}, 1.25 \mathrm{mM} \mathrm{TMB} / 6 \% \mathrm{H}_{2} \mathrm{O}_{2}$ mixture alone (red line) and

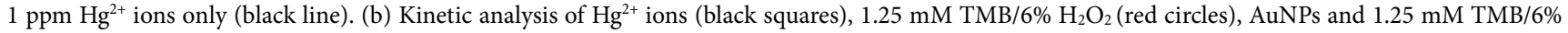
$\mathrm{H}_{2} \mathrm{O}_{2}$ (blue triangles) and AuNPs with $1.25 \mathrm{mM} \mathrm{TMB} / 6 \% \mathrm{H}_{2} \mathrm{O}_{2}$ in the presence of $1 \mathrm{ppm} \mathrm{Hg}^{2+}$ ions (cyan triangles). All experiments were conducted over a $10 \mathrm{~min}$ incubation period at room temperature. (c) Linear relationship between $\mathrm{Hg}^{2+}$ concentration and the enhanced catalytic activity of the bare-nanozyme $\left(R^{2}=0.996\right)$ in $\mathrm{dH}_{2} \mathrm{O}$. (d) Catalytic performance of the bare nanozyme for the detection of $\mathrm{Hg}^{2+}$ ions in a d $\mathrm{H}_{2} \mathrm{O}$ matrix (red bars) and in seawater conditions $(3.5 \% \mathrm{NaCl}$, black bars).

AuNPs could be enhanced by $62.2 \%$ in the presence of $\mathrm{Hg}^{2+}$ ions (Fig. S4(b) in the ESM). These results confirm that the formation of $\mathrm{Au}-\mathrm{Hg}$ amalgam can significantly improve the peroxidase-mimicking potential of the bare-nanozyme, which agrees with the previous report [30]. This mechanism could therefore be employed for the detection of $\mathrm{Hg}^{2+}$ ions in a $\mathrm{dH}_{2} \mathrm{O}$ matrix (Figs. 3(c) and 3(d), red bars). However, to investigate the capabilities of the bare-nanozyme for the detection of $\mathrm{Hg}^{2+}$ ions in harsh water matrices, $\mathrm{Hg}^{2+}$ concentrations were spiked into saline solution $(3.5 \% \mathrm{NaCl})$ prior to interaction with the nanozyme. The results in Fig. 3(d) (black bars) indicate that the strong electrolyte environment induces the aggregation of AuNPs, resulting in suppressed catalytic activity of the nanozyme by up to $88.4 \%$, even in the presence of $\mathrm{Hg}^{2+}$. This can be attributed to the high electrolyte environment increasing the particle size or size of aggregated clusters, thus reducing their surface area-to-volume ratio and subsequently their enzymemimicking properties, as reported previously [51]. Therefore, these results suggest that the aggregation state of the AuNP has more influence on their catalytic activity than the formation of $\mathrm{Au}-\mathrm{Hg}$ amalgam.

\subsection{OEG functionalisation improves the colloidal} stability of the nanozyme, thereby enabling the detection of $\mathrm{Hg}^{2+}$ ions in harsh water matrices

As discussed, AuNP aggregation has a detrimental effect on the catalytic activity regardless of the presence of $\mathrm{Hg}^{2+}$, thus in order to detect $\mathrm{Hg}^{2+}$ in a high electrolyte water sample it was crucial to stabilise the bare-nanozyme with OEG. The functionalisation of AuNPs with OEG was conducted according to a previous method with minor adjustments [45]. The OEG molecule (O-(2-mercaptoethyl)-O'-methyl-hexa(ethylene glycol)) was functionalised onto the AuNP surface via chemisorption of thiol groups. A shift in LSPR peak from 519 (bare-AuNP) to $522 \mathrm{~nm}$ (OEG-AuNP) was observed (Fig. S5 in the ESM), indicating an increased refractive index at the particle surface due to adsorbed OEG molecules. FTIR was conducted to characterise the functionalisation of AuNPs with OEG (Fig. S6 in the ESM). The result indicates the presence of ethylene glycol molecules on the surface of AuNPs, thus confirming the successful functionalisation.

The OEG-AuNPs show excellent stability in a range of $\mathrm{NaCl}$ concentrations $(0-20 \%, \sim 0-3.4 \mathrm{M})$ (Fig. S7(a) in the ESM) and pHs (1-14) (Fig. S7(b) in the ESM), and can remain stable for several months in $\mathrm{dH}_{2} \mathrm{O}$ when stored at $4{ }^{\circ} \mathrm{C}$. The stability of the particles can be attributed to the hydrophilic nature of ethylene glycol forming a protective layer around the AuNP surface, which shields from high electrolyte environments. The OEG-AuNP when tested in acidic conditions ( $\mathrm{pH} \mathrm{1-3)}$ a broadening in LSPR peak was observed $(\sim 50 \mathrm{~nm})$. This slight shift in wavelength can be attributed to a reduction in interparticle distance, however not particle aggregation, as the UV-vis spectra (Fig. S7(b) in the ESM) can confirm particle stability in acidic conditions. Nonetheless, functionalising the AuNPs with OEG can provide stability which exceeds the limits required for a seawater matrix, as the $\mathrm{pH}$ of seawater is $\sim 7-8$ and the $\mathrm{NaCl}$ concentration is $\sim 3.5 \%(\sim 0.6 \mathrm{M})$. Also, 
the bare-nanozyme lacks stability over $0.3 \%(0.05 \mathrm{M}) \mathrm{NaCl}$, which is much lower than the concentration found in seawater and highlights the improvements in particle stability after functionalisation with OEG. Additionally, the zeta-potential of the bare-AuNP was $-48.1 \mathrm{mV}$, whilst the zeta-potential of

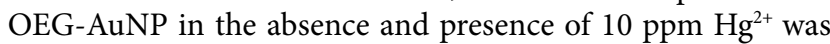
-40.8 and $-38.7 \mathrm{mV}$, respectively. The change in zeta potential can be attributed to the desorption of capping agent, citrate ions which have a strong negative charge due to the formation of Au-S bonds, after the addition of the OEG molecules. The results also indicate that in the presence of $\mathrm{Hg}^{2+}$ the charge of the OEG-AuNP becomes less negative, due to the desorption of capping agent and the two positive charges held by $\mathrm{Hg}^{2+}$ ions [52]. Overall, this demonstrates the excellent stability of OEG-AuNP and their potential for detecting $\mathrm{Hg}^{2+}$ in a wide range of environments and matrices.

Figure 4 presents the catalytic activity of OEG-AuNP in the absence and presence of $\mathrm{Hg}^{2+}$. After 30 min incubation with $1.25 \mathrm{mM} \mathrm{TMB} / 6 \% \mathrm{H}_{2} \mathrm{O}_{2}$, the OEG-AuNP demonstrates suppressed catalytic activity (Fig. 4(a), red line) in comparison to the bare-AuNP, confirmed by the two distinct absorption peaks at 370 and $650 \mathrm{~nm}$ (Fig. 4(a), black line). In the absence of $\mathrm{Hg}^{2+}$ the OEG-AuNP cannot catalyse the oxidation reaction of TMB, as the hydrophilic ethylene glycol layer shields the surface, therefore blocking the transferring of oxygen atoms required for the reaction. However, in the presence of $\mathrm{Hg}^{2+}$ ions $(10 \mathrm{ppm})$, the catalytic activity of OEG-AuNP is recovered by $\sim 75 \%$ after $30 \mathrm{~min}$ incubation (Fig. 4(b), blue triangles). This suggests that the enhanced peroxidase-like activity of the stabilised OEG-AuNP could also be attributed to $\mathrm{Au}-\mathrm{Hg}$ amalgam formation, due to the strong aurophillic interactions which exist between $\mathrm{Au}$ and $\mathrm{Hg}$.
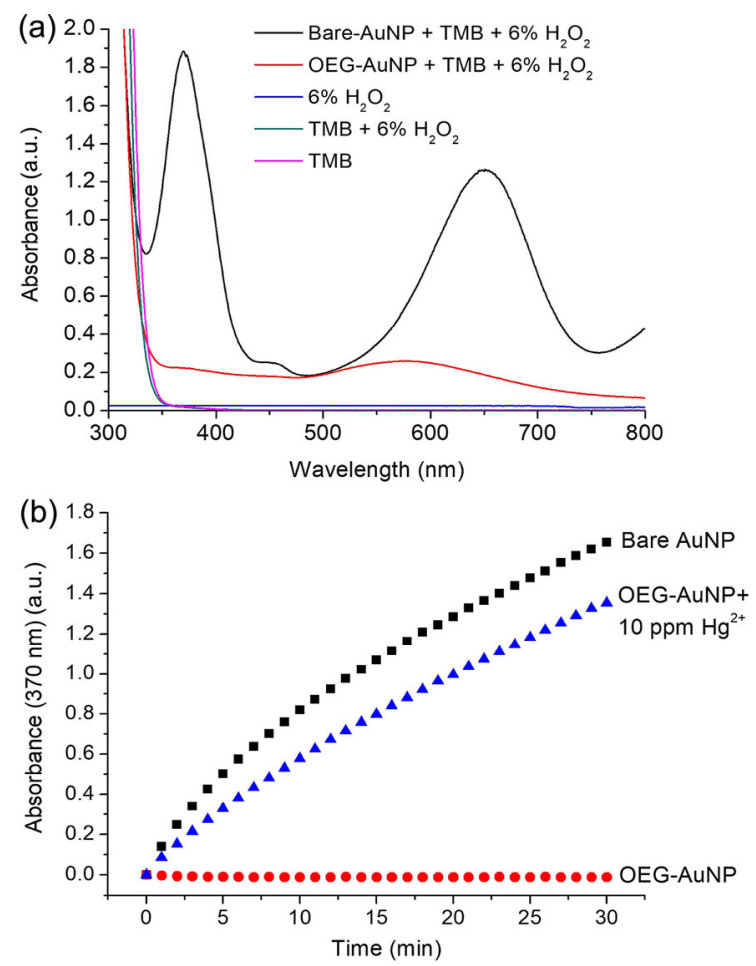

Figure 4 Experiment to confirm the suppression of OEG-AuNPs $\left(\mathrm{OD}_{\oplus 520 \mathrm{~nm}}=0.5,0.85 \times 10^{-9} \mathrm{M}\right)$ nanozyme activity, and recovery after incubation with $\mathrm{Hg}^{2+}$ ions (10 ppm). (a) Full wavelength spectra of bare-AuNP (black line) and OEG-functionalised AuNP (red line) after incubation with $1.25 \mathrm{mM} \mathrm{TMB} / 6 \% \mathrm{H}_{2} \mathrm{O}_{2}$ for $30 \mathrm{~min}$. (b) Scanning kinetic analysis of bare-AuNP (black squares), OEG-functionalised AuNP (red circles) and OEG-AuNP incubated with $\mathrm{Hg}^{2+}$ ions (10 ppm) (blue triangles) all with $1.25 \mathrm{mM} \mathrm{TMB} / 6 \% \mathrm{H}_{2} \mathrm{O}_{2}$ at a fixed wavelength of $370 \mathrm{~nm}$ over $30 \mathrm{~min}$.
TEM was carried out to characterise the size of bare-AuNPs (Fig. S1(a) in the ESM), and OEG-functionalised AuNP (Fig. S1(c) in the ESM). As we have discussed previously, aggregation of AuNPs has a strong effect on their catalytic activity. Therefore, it was important to ensure that the preparation of OEG-AuNP, or addition of $\mathrm{Hg}^{2+}$ ions was not affecting the aggregation state of the AuNPs, as this would be detrimental to the catalytic efficiency, and overall sensitivity of the assay. The TEM images (Fig. S1 in the ESM) and corresponding UV-vis absorption spectra (Fig. S8 in the ESM) can confirm that OEG and $\mathrm{Hg}^{2+}$ ions, do not dramatically influence the AuNP aggregation state. Interestingly, in the presence of $\mathrm{Hg}^{2+}$ the particles appear to coalesce (Fig. 5(a), red arrows) transforming the shape of the spherical AuNPs, however this does not cause particle aggregation. Further characterisation techniques were conducted to confirm the formation of Au-Hg amalgam, including HRTEM (Fig. 5(b)), HAADF-STEM (Fig. 5(b), inset 1), elemental mapping (Fig. 5(b), inset 2-3) and EDS (Fig. 5(c)). It is observed from the HRTEM image (Fig. 5(b)) the formation of an $\mathrm{Au}-\mathrm{Hg}$ nanostructure, and the elemental mapping (Fig. 5(b), inset 1-3) performed using HAADF-STEM imaging indicates the presence of both $\mathrm{Au}$ and $\mathrm{Hg}$ within one nanostructure. The EDS spectrum (Fig. 5(c)) could further confirm the composition, highlighting the presence of both $\mathrm{Au}$ and $\mathrm{Hg}$ within the same amalgamated $\mathrm{Au}-\mathrm{Hg}$ nanostructures.

Thus far, the results can support that our sensing mechanism is based on the ability of $\mathrm{Hg}^{2+}$ (ions) to become reduced to
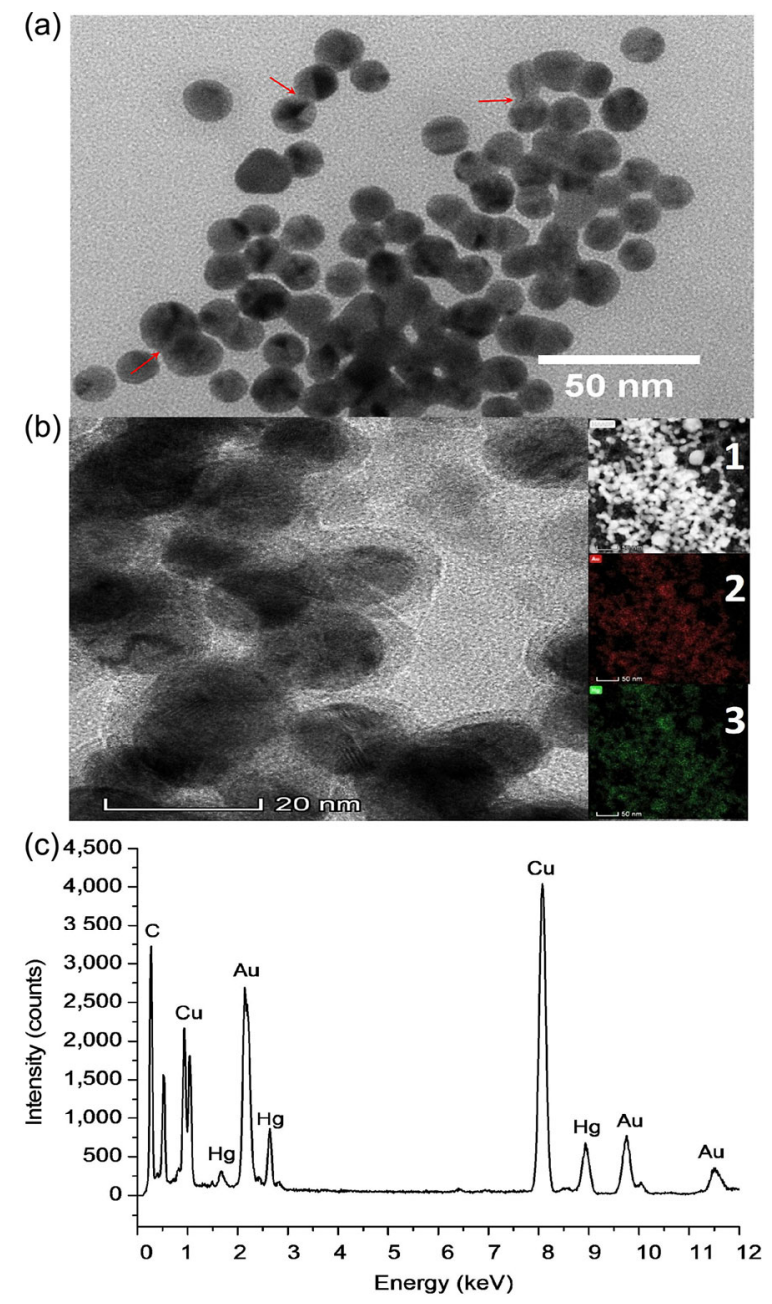

Figure 5 Characterisation of OEG-AuNP in the presence of $\mathrm{Hg}^{2+}(100 \mathrm{ppm})$. (a) TEM analysis indicates particle coalescence upon amalgamation (red arrows). (b) HRTEM. Inset: (1) HAADF-STEM, elemental mapping of (2) $\mathrm{Au}$ and (3) $\mathrm{Hg}^{2+}$. (c) EDS of the area in inset 1. 
$\mathrm{Hg}^{0}$ (metal) to allow the formation of $\mathrm{Au}-\mathrm{Hg}$ amalgamation, through strong aurophilic interactions. The metallic alloy can facilitate the oxidation of TMB substrate further in the presence of $\mathrm{H}_{2} \mathrm{O}_{2}$, through an electron transfer process which occurs at the surface of the $\mathrm{Au}-\mathrm{Hg}$ nanostructure, resulting in enhanced reaction rates and an intense (vivid)-blue coloured product. However, $\mathrm{Hg}^{2+}$ ions are most abundant and problematic within seawater causing serious concerns for seafood consumers. Findings in the research indicate that the $\mathrm{Au}-\mathrm{Hg}$ alloy is not able to catalyse for the oxidation of TMB substrate in seawater conditions (i.e., $3.5 \% \mathrm{NaCl}$ ), due to particle aggregation, thus making this method unsuitable for detecting $\mathrm{Hg}^{2+}$ ions in harsh water matrices. When the AuNPs are functionalised with OEG, the particles are not only stable at high salt concentrations and various pHs, but interestingly the nanozyme activity is inhibited and only recovered by the presence of $\mathrm{Hg}^{2+}$ ions (Scheme 1). The amalgamation-promoting nanozyme activity of OEG-AuNPs can provide a sensitive and specific detection platform for detecting $\mathrm{Hg}^{2+}$ in different conditions, including high salt concentrations, varied $\mathrm{pH}$ and improve the approaches applicability to harsh water matrices. Extensive kinetic analysis of the catalytic activity of OEG-AuNPs in the presence of various concentrations of $\mathrm{Hg}^{2+}$ ions is presented in Fig. S9 in the ESM. The results indicate that OEG-AuNP do not exhibit strong peroxidase-like activity unless $\mathrm{Hg}^{2+}$ ions are present.

\subsection{Sensitivity and selectivity of the $\mathrm{Au}-\mathrm{Hg}$ amalgam in water samples}

Figure 6(a) demonstrates the calibration curve $\left(R^{2}=0.999\right)$ and linear fitting of catalytic activity increase as a function of $\mathrm{Hg}^{2+}$ concentration $\left(R^{2}=0.996\right)$ in a $\mathrm{dH}_{2} \mathrm{O}$ matrix. Under optimal assay conditions the calibration curve provided a working range from $10 \mathrm{ppb} \mathrm{Hg}^{2+}$ to $200 \mathrm{ppb} \mathrm{Hg}^{2+}$, and the relationship between the absorbance at $370 \mathrm{~nm}$ against $\mathrm{Hg}^{2+}$ concentration was linear in a range between $10 \mathrm{ppb}$ and
$60 \mathrm{ppb} \mathrm{Hg}^{2+}$. The limit of detection (LOD) was calculated at a signal to noise ratio of 3 times the standard deviation $(\sigma)$ of the blank, with a minimum detection limit of $0.9 \mathrm{ppb} \mathrm{Hg}^{2+}$ in $\mathrm{dH}_{2} \mathrm{O}$ conditions (Table 1). The selectivity of the colorimetric assay was tested against thirteen metal ions $\left(\mathrm{K}^{+}, \mathrm{Zn}^{2+}, \mathrm{Na}^{+}\right.$, $\left.\mathrm{Mn}^{2+}, \mathrm{Ag}^{3+}, \mathrm{Al}^{3+}, \mathrm{Co}^{2+}, \mathrm{Ca}^{2+}, \mathrm{Fe}^{2+}, \mathrm{Mg}^{2+}, \mathrm{Bi}^{3+}, \mathrm{Li}^{4+}, \mathrm{Sn}^{4+}\right)$ to ensure the assay was specific to $\mathrm{Hg}^{2+}$ detection (Fig. 6(b)), and to confirm that the enhancement of OEG-AuNP nanozyme activity was only attributed to the presence of $\mathrm{Hg}^{2+}$ ions. The concentrations of all metal ions including $\mathrm{Hg}^{2+}$ were fixed at $10 \mathrm{ppm}$. When the concentration of metal ions was over 10,000 times the assay LOD, the nanozyme activity of the OEG-AuNP was not recovered or enhanced in the presence of any other metal ions, except $\mathrm{Hg}^{2+}$ ions. This excellent selectivity can be attributed to the high affinity $\mathrm{Hghas}$ for $\mathrm{Au}$, and their ability to amalgamate. Thus, in a real water matrix the assay should not be hindered by the presence of other metal ions, which confirms its applicability to complex water samples.

To determine the applicability of the assay in real water matrices, drinking water (tap and bottled water) samples were analysed, and a saline solution $(3.5 \% \mathrm{NaCl})$ to represent seawater. $\mathrm{Hg}^{2+}$ concentrations ranging from $0-1 \mathrm{ppm}$ were spiked into all water matrices and the calibration range and linear fittings were determined (Fig. S10 in the ESM). The results showed good linearity between $\mathrm{Hg}^{2+}$ concentrations and the absorbance at $370 \mathrm{~nm}$, with LODs identified as $2 \mathrm{ppb}\left(R^{2}=0.997\right), 2 \mathrm{ppb}$ $\left(R^{2}=0.995\right)$ and $13 \mathrm{ppb}\left(R^{2}=0.994\right)$ for tap water, bottled water and saline solution, respectively (Table 1$)$. For validation purposes a coastal seawater CRM was also spiked with $\mathrm{Hg}^{2+}$ concentrations ranging from $0-1 \mathrm{ppm}$. The results also showed good linearity $\left(R^{2}=0.988\right)$ and a LOD of $10 \mathrm{ppb}$ was detectable (Fig. S11 in the ESM), which is slightly lower than that of the saline solution. The coefficient of variation $(\mathrm{CV})(\%)$ was calculated to confirm assay repeatability and was based on triplicate samples over consecutive days $(n=3)$, using the

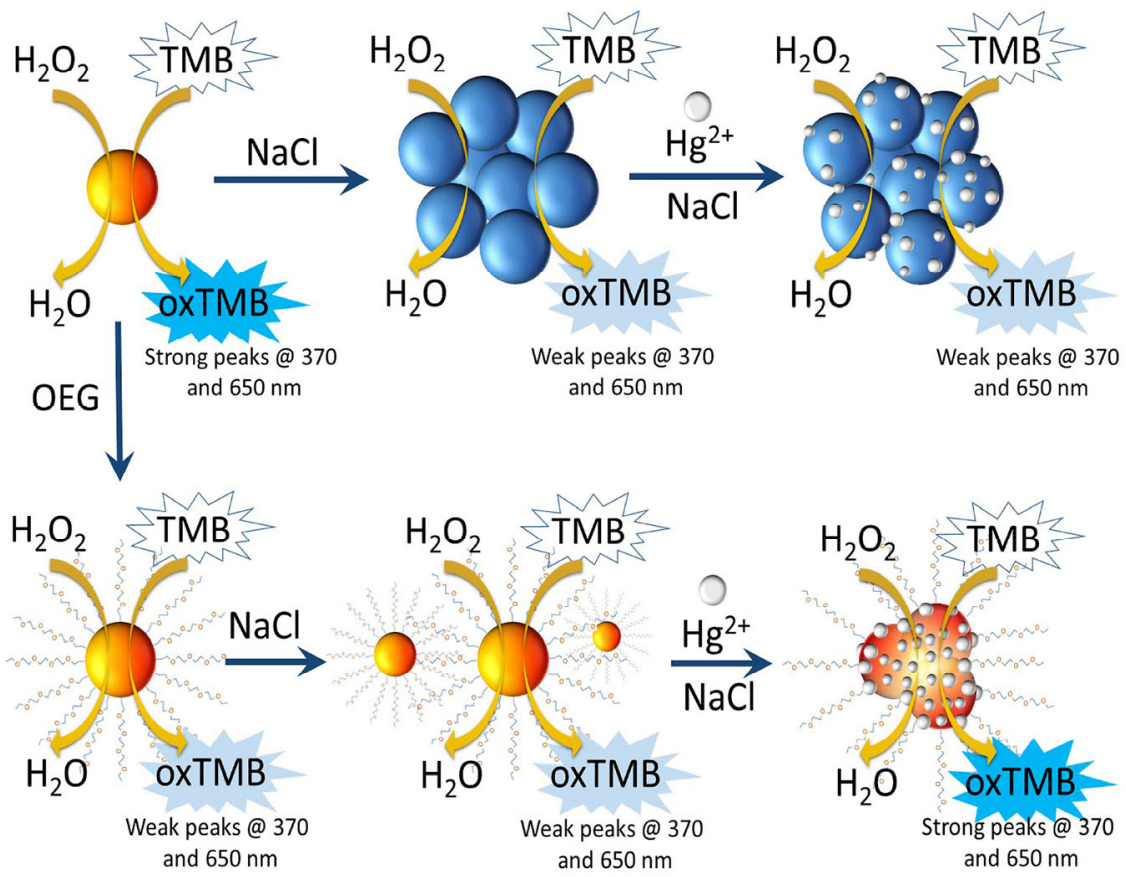

Scheme 1 Working principle of the sensing mechanism for the colorimetric detection of $\mathrm{Hg}^{2+}$. Above row: bare-AuNPs can strongly catalyse for the oxidation of TMB substrate in the presence of $\mathrm{H}_{2} \mathrm{O}_{2}$. However, in the presence of $3.5 \% \mathrm{NaCl}$ (to simulate the salt concentration of seawater) the catalytic activity of the AuNP is significantly reduced due to particle aggregation, even with the formation of $\mathrm{Au}-\mathrm{Hg}$ amalgam. Below row: functionalising the AuNPs with OEG provides improved stability in high electrolyte environments. However, the catalytic activity of the OEG-AuNP is suppressed, and only recovered in the presence of $\mathrm{Hg}^{2+}$ ions. The mechanism can be attributed to the formation of $\mathrm{Au}-\mathrm{Hg}$ amalgam, which can provide a colorimetric sensor applicable to seawater conditions. 

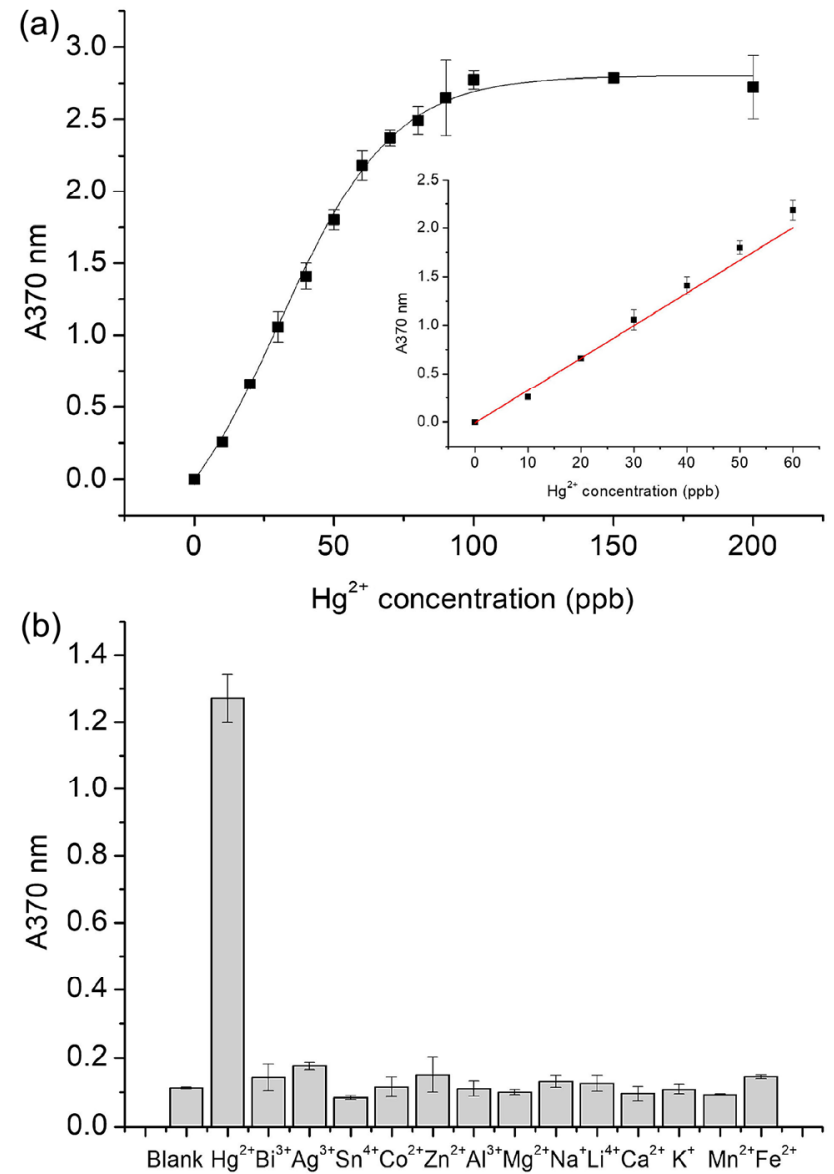

Figure 6 Illustrating assay sensitivity and specificity in $\mathrm{dH}_{2} \mathrm{O}$. (a) Analysis of OEG-AuNP nanozyme activity with increasing concentrations of $\mathrm{Hg}^{2+}$ ions. Inset: the linear relationship between $\mathrm{Hg}^{2+}$ concentration and enhanced nanozyme activity $\left(R^{2}=0.996\right)$. Data was normalised relative to the blank sample (zero). (b) Analysis of OEG-AuNP nanozyme activity in the presence of additional metal ions (all at $10 \mathrm{ppm}$ ).

Table 1 Nanozyme activity of OEG-AuNP as a function of $\mathrm{Hg}^{2+}$ concentration, analysed in water matrices after $10 \mathrm{~min}$ incubation with $1.25 \mathrm{mM} \mathrm{TMB} / 6 \% \mathrm{H}_{2} \mathrm{O}_{2}$. The table demonstrates the sensitivity of the assay in $\mathrm{dH}_{2} \mathrm{O}$, tap water, bottled water, saline solution and certified coastal seawater reference material (CRM). Validation was also conducted to assess the coefficient of variation (\%) and \% recovery (both calculated from the average of triplicate samples $(n=3)$ over three consecutive days)

\begin{tabular}{|c|c|c|c|c|}
\hline Matrix & $\begin{array}{l}\text { LOD } \\
(\mathrm{ppb})\end{array}$ & $\begin{array}{c}\mathrm{Hg}^{2+} \text { concentration } \\
(\mathrm{ppb})\end{array}$ & $\begin{array}{l}\mathrm{CV} \\
(\%)\end{array}$ & $\begin{array}{c}\text { Recovery } \\
(\%)\end{array}$ \\
\hline \multirow{3}{*}{$\mathrm{dH}_{2} \mathrm{O}$} & \multirow{3}{*}{0.9} & 20 & 2.3 & 89.6 \\
\hline & & 40 & 5.5 & 98.6 \\
\hline & & 80 & 3.0 & 97.1 \\
\hline \multirow{3}{*}{ Tap water } & \multirow{3}{*}{2} & 10 & 14.7 & 87.9 \\
\hline & & 20 & 7.1 & 82.4 \\
\hline & & 40 & 17.3 & 75.8 \\
\hline \multirow{3}{*}{ Bottled water } & \multirow{3}{*}{2} & 10 & 11.5 & 103.9 \\
\hline & & 20 & 6.4 & 105.3 \\
\hline & & 40 & 13.6 & 111.8 \\
\hline \multirow{3}{*}{$\begin{array}{l}\mathrm{Hg}^{2+} \text { seawater } \\
\text { CRM }\end{array}$} & \multirow{3}{*}{10} & 20 & 10.1 & 103.6 \\
\hline & & 60 & 5.6 & 97.8 \\
\hline & & 100 & 5.7 & 95.8 \\
\hline \multirow{3}{*}{ Saline solution } & \multirow{3}{*}{13} & 40 & 7.4 & 91.0 \\
\hline & & 80 & 9.8 & 93.0 \\
\hline & & 160 & 12.9 & 123.7 \\
\hline
\end{tabular}

average $(x)$ and $\sigma(n=3)$. The CV\% for all water samples fell below $17.3 \%$. The $\%$ recovery was also calculated to confirm the reliability of the assay and was based on an average of triplicate spiked samples over consecutive days $(n=3)$ against the developed calibrations (known concentrations). The \% recovery results all fell into an acceptable range of $76 \%$ to $124 \%$. Therefore, the results from the spiked sample analysis and validation can confirm that the assay is repeatable and reliable.

The LOD had increased $\sim 2$ times in tap and bottled water in comparison to the $\mathrm{dH}_{2} \mathrm{O}$ conditions, however these limits can nonetheless meet the MCLs for $\mathrm{Hg}^{2+}$ in drinking water (2 ppb), as set by the EPA and WHO. Additionally, the LOD in seawater CRM and saline solution had increased to $10 \mathrm{ppb}$ and $13 \mathrm{ppb}$, respectively however this can be attributed to matrix effects within the complex water samples, more specifically the decomposition of hydrogen peroxide in the presence of chloride interfering with the oxidation reaction [53]. However, due to the excellent stability of OEG-AuNPs and the recovery of nanozyme activity in the presence of $\mathrm{Au}-\mathrm{Hg}$ nanoalloys, it was still possible to quantify LODs for oxTMB in complicated water matrices, using spectroscopy. Furthermore, the concentration of $\mathrm{Hg}^{2+}$ in seawater is commonly between $60-80 \mathrm{ppb}$ in shallow waters, therefore the assay should be capable of detecting within this range and highlights its potential to analyse real seawater samples. Finally, dangerous levels of $\mathrm{Hg}^{2+}$ within seafood are most abundant within larger species (e.g., tuna, shark, swordfish), with levels ranging from $100 \mathrm{ppb}$ ( $\mathrm{min}$ ) to $4.5 \mathrm{ppm}$ (max) [54]. Therefore, the assay shows not only good applicability to drinking water and seawater, but also has the potential for seafood analysis in the future.

\section{Conclusion}

Overall, a sensitive and highly specific colorimetric assay for the detection of $\mathrm{Hg}^{2+}$ ions, which is based on recovering the nanozyme activity of OEG-functionalised AuNPs was successfully developed. We discovered that bare-AuNPs witness $\sim 73.7 \%$ decline in catalytic efficiency when faced with $\mathrm{NaCl}$ concentrations above $1.168 \%$, which is much lower than the concentration of $\mathrm{NaCl}$ in seawater (3.5\%). In addition, steady-state kinetic parameters reveal that the peroxidase-like activity of the bare-nanozyme could be enhanced by $62.2 \%$ in the presence of $\mathrm{Hg}^{2+}$. However, when faced with high concentrations of electrolytes the catalytic activity of the $\mathrm{Au}-\mathrm{Hg}$ amalgam was significantly reduced (by up to $88.4 \%$ ). OEGAuNPs demonstrated high stability in a range of $\mathrm{NaCl}$ concentrations (0-20\%) and $\mathrm{pHs}(1-14)$, thus can improve the applications of $\mathrm{Hg}^{2+}$ detection to complex water matrices. Surprisingly, the catalytic activity of the OEG-AuNP was suppressed due to the ethylene glycol layer surrounding the nanoparticle surface, however it was found that this activity could be recovered in the presence of $\mathrm{Hg}^{2+}$ ions.

Characterisation techniques confirmed that the sensing mechanism was due to $\mathrm{Au}-\mathrm{Hg}$ amalgamation, which allowed the development of a highly specific colorimetric assay with sensitivity down to parts per trillion level $\left(0.9 \mathrm{ppb}\right.$ in $\left.\mathrm{dH}_{2} \mathrm{O}\right)$. Real sample analysis could determine detection limits for $\mathrm{Hg}^{2+}$ as $2 \mathrm{ppb}$ in drinking water (tap and bottled water) and 10-13 ppb in high salinity samples (seawater CRM and saline solution, respectively). Due to the excellent stability of OEG-AuNPs the sensitivity was not influenced dramatically by the matrix, demonstrating the assays effectiveness for water analysis. In addition, the total assay time takes $45 \mathrm{~min}$, requires only a few reagents and can be conducted at room temperature, highlighting its low-cost and practicality. Overall, the assay 
has the ability to improve the on-site analysis of drinking water, seawater samples and potentially seafood samples. Thus, it contributes to the protection of human health, aquaculture and the environment from toxic $\mathrm{Hg}^{2+}$ contamination.

\section{Acknowledgements}

The author N. L. and C. M. thank the PhD studentship support from the Department of Employment and Learning for Northern Ireland (DEL); C. C. thanks the strong support from the Central Research Support Funds of Queen's University Belfast via a start-up grant.

Electronic Supplementary Material: Supplementary material (TEM images of (a) stable bare-AuNP and (b) aggregated AuNPs, in the presence of $\mathrm{dH}_{2} \mathrm{O}$ and $0.5 \mathrm{M} \mathrm{NaCl}$, respectively (c) OEG-functionalised AuNPs (Fig. S1); UV-vis spectra of AuNP treated with different $\mathrm{NaCl}$ concentrations $(0-0.5 \mathrm{M})$ (Fig. S2); the effect of $\mathrm{NaCl}$ on AuNP peroxidase-like activity (Fig. S3); Michaelis-Menten kinetic analysis (Fig. S4); UV-vis analysis of bare-AuNP and OEG-AuNP (Fig. S5); FTIR spectra for OEG-AuNP characterisation (Fig. S6); full wavelength spectra to examine the stability of AuNP functionalised with OEG in the presence of $0-20 \% \mathrm{NaCl}$ and PBS buffer $\mathrm{pH} 1-14$ (Fig. S7); UV-vis analysis to confirm the stability of bare-AuNP and OEG-AuNP in the presence of $\mathrm{Hg}^{2+}$ ions (10 ppm) (Fig. S8); scanning kinetic analysis of OEG-AuNP nanozyme activity in the presence of $\mathrm{Hg}^{2+}$ concentrations (Fig. S9); nanozyme activity of OEG-AuNP as a function of $\mathrm{Hg}^{2+}$ concentration, analysed in water matrices demonstrating the sensitivity and applicability of the assay (Fig. S10); Linear relationship between spiked $\mathrm{Hg}^{2+}$ concentration and recovered nanozyme activity for OEG-AuNP analysed in a coastal seawater $\mathrm{Hg}^{2+}$ certified reference material (CRM) (Fig. S11)) is available in the online version of this article at https://doi.org/10.1007/s12274-020-2731-y.

Open Access This article is licensed under a Creative Commons Attribution 4.0 International License, which permits use, sharing, adaptation, distribution and reproduction in any medium or format, as long as you give appropriate credit to the original author(s) and the source, provide a link to the Creative Commons licence, and indicate if changes were made.

The images or other third party material in this article are included in the article's Creative Commons licence, unless indicated otherwise in a credit line to the material. If material is not included in the article's Creative Commons licence and your intended use is not permitted by statutory regulation or exceeds the permitted use, you will need to obtain permission directly from the copyright holder.

To view a copy of this licence, visit http://creativecommons.org/ licenses/by/4.0/.

\section{References}

[1] Schuster, P. F.; Schaefer, K. M.; Aiken, G. R.; Antweiler, R. C.; Dewild, J. F.; Gryziec, J. D.; Gusmeroli, A.; Hugelius, G.; Jafarov, E.; Krabbenhoft, D. P. et al. Permafrost stores a globally significant amount of mercury. Geophys. Res. Lett. 2018, 45, 1463-1471.

[2] Poornima, V.; Alexandar, V.; Iswariya, S.; Perumal, P. T.; Uma, T. S. Gold nanoparticle-based nanosystems for the colorimetric detection of $\mathrm{Hg}^{2+}$ ion contamination in the environment. RSC Adv. 2016, 6, 46711-46722.

[3] United States Environmental Protection Agency (EPA). National Primary Drinking Water Regulations [Online]. https://www.epa.gov/ ground-water-and-drinking-water/national-primary-drinking-waterregulations (accessed Mar 05, 2020).
[4] World Health Organization (WHO). Guidelines for Drinking-Water Quality Third Edition. Geneva, World Health Organization [Online]. http://www.who.int/water_sanitation_health/dwq/GDWQ2004web.pdf (accessed Sep 14, 2019).

[5] Lamborg, C. H.; Hammerschmidt, C. R.; Bowman, K. L.; Swarr, G. J.; Munson, K. M.; Ohnemus, D. C.; Lam, P. J.; Heimburger, L. E.; Rijkenberg, M. J.; Saito, M. A. A global ocean inventory of anthropogenic mercury based on water column measurements. Nature 2014, 512, 65-68.

[6] Bloxham, M. J.; Hill, S. J.; Worsfold, P. J. Determination of trace metals in sea-water and the on-line removal of matrix interferences by flow injection with inductively coupled plasma mass spectrometric detection. J. Anal. At. Spectrom. 1994, 9, 935-938.

[7] Wang, C. I.; Huang, C. C.; Lin, Y. W.; Chen, W. T.; Chang, H. T. Catalytic gold nanoparticles for fluorescent detection of mercury(II) and lead(II) ions. Anal. Chim. Acta 2012, 745, 124-130.

[8] Zhou, Q. X.; Lei, M.; Liu, Y. L.; Wu, Y. L.; Yuan, Y. Y. Simultaneous determination of cadmium, lead and mercury ions at trace level by magnetic solid phase extraction with Fe@Ag@Dimercaptobenzene coupled to high performance liquid chromatography. Talanta 2017, $175,194-199$.

[9] Sharma, R.; Ragavan, K. V.; Thakur, M. S.; Raghavarao, K. S. M. S. Recent advances in nanoparticle based aptasensors for food contaminants. Biosens. Bioelectron. 2015, 74, 612-627.

[10] Lee, J. S.; Han, M. S.; Mirkin, C. A. Colorimetric detection of mercuric ion $\left(\mathrm{Hg}^{2+}\right)$ in aqueous media using DNA-functionalized gold nanoparticles. Angew. Chem., Int. Ed. 2007, 46, 4093-4096.

[11] Li, D.; Wieckowska, A.; Willner, I. Optical analysis of $\mathrm{Hg}^{2+}$ ions by oligonucleotide-gold-nanoparticle hybrids and DNA-based machines. Angew. Chem. 2008, 120, 3991-3995.

[12] Liu, C. W.; Hsieh, Y. T.; Huang, C. C.; Lin, Z. H.; Chang, H. T. Detection of mercury(II) based on $\mathrm{Hg}^{2+}$-DNA complexes inducing the aggregation of gold nanoparticles. Chem. Commun. 2008, 2242-2244.

[13] Ma, Y. J.; Jiang, L.; Mei, Y. J.; Song, R. B.; Tian, D. B.; Huang, H. Colorimetric sensing strategy for mercury(II) and melamine utilizing cysteamine-modified gold nanoparticles. Analyst 2013, 138, 53385343.

[14] Lin, C. Y.; Yu, C. J.; Lin, Y. H.; Tseng, W. L. Colorimetric sensing of silver(I) and mercury(II) ions based on an assembly of tween 20-stabilized gold nanoparticles. Anal. Chem. 2010, 82, 6830-6837.

[15] Guo, Y. M.; Wang, Z.; Qu, W. S.; Shao, H. W.; Jiang, X. Y. Colorimetric detection of mercury, lead and copper ions simultaneously using protein-functionalized gold nanoparticles. Biosens. Bioelectron. 2011, 26, 4064-4069.

[16] Su, D. Y.; Yang, X.; Xia, Q. D.; Chai, F.; Wang, C. G.; Qu, F. Y. Colorimetric detection of $\mathrm{Hg}^{2+}$ using thioctic acid functionalized gold nanoparticles. RSC Adv. 2013, 3, 24618-24624.

[17] McVey, C.; Logan, N.; Thanh, N. T. K.; Elliott, C.; Cao, C. Unusual switchable peroxidase-mimicking nanozyme for the determination of proteolytic biomarker. Nano Res. 2019, 12, 509-516.

[18] Luo, W. J.; Zhu, C. F.; Su, S.; Li, D.; He, Y.; Huang, Q.; Fan, C. H. Self-catalyzed, self-limiting growth of glucose oxidase-mimicking gold nanoparticles. ACS Nano 2010, 4, 7451-7458.

[19] Zheng, X. X.; Liu, Q.; Jing, C.; Li, Y.; Li, D.; Luo, W. J.; Wen, Y. Q.; He, Y.; Huang, Q.; Long, Y. T. et al. Catalytic gold nanoparticles for nanoplasmonic detection of DNA hybridization. Angew. Chem., Int. Ed. 2011, 50, 11994-11998.

[20] Shin, H. Y.; Cho, S.; Kim, M. I. Enzyme-free colorimetric detection of glucose using a composite entrapping gold and magnetic nanoparticles within an agarose gel matrix. J. Nanosci. Nanotechnol. 2017, 17, 7971-7977.

[21] He, W. W.; Zhou, Y. T.; Wamer, W. G.; Hu, X. N.; Wu, X. C.; Zheng, Z.; Boudreau, M. D.; Yin, J. J. Intrinsic catalytic activity of Au nanoparticles with respect to hydrogen peroxide decomposition and superoxide scavenging. Biomaterials 2013, 34, 765-773.

[22] Liang, H.; Wu, Y.; Qu, X. Y.; Li, J. Y.; Li, J. Au@Pt nanoparticles as catalase mimics to attenuate tumor hypoxia and enhance immune cell-mediated cytotoxicity. Nanotechnology 2017, 28, 465702.

[23] Lin Y. W.; Huang, C. C.; Chang, H. T. Gold nanoparticle probes for the detection of mercury, lead and copper ions. Analyst 2011, 136, 863-871. 
[24] Lien, C. W.; Tseng, Y. T.; Huang, C. C.; Chang, H. T. Logic control of enzyme-like gold nanoparticles for selective detection of lead and mercury ions. Anal. Chem. 2014, 86, 2065-2072.

[25] Chen, Z. B.; Tan, L. L.; Wang, S. X.; Zhang, Y. M.; Li, Y. H. Sensitive colorimetric detection of $\mathrm{K}(\mathrm{I})$ using catalytically active gold nanoparticles triggered signal amplification. Biosens. Bioelectron. 2016, 79, 749-757.

[26] Jv, Y.; Li, B. X.; Cao, R. Positively-charged gold nanoparticles as peroxidiase mimic and their application in hydrogen peroxide and glucose detection. Chem. Commun. 2010, 46, 8017-8019.

[27] Tseng, C. W.; Chang, H. Y.; Chang, J. Y.; Huang, C. C. Detection of mercury ions based on mercury-induced switching of enzyme-like activity of platinum/gold nanoparticles. Nanoscale 2012, 4, 6823-6830.

[28] Wang, G. L.; Xu, X. F.; Cao, L. H.; He, C. H.; Li, Z. J.; Zhang, C. Mercury(II)-stimulated oxidase mimetic activity of silver nanoparticles as a sensitive and selective mercury(II) sensor. RSC $A d v$. 2014, 4, $5867-5872$.

[29] Sui, N.; Liu, F. Y.; Wang, K.; Xie, F. X.; Wang, L. N.; Tang, J. J.; Liu, M. H.; Yu, W. W. Nano Au-Hg amalgam for $\mathrm{Hg}^{2+}$ and $\mathrm{H}_{2} \mathrm{O}_{2}$ detection. Sens. Actuators B Chem. 2017, 252, 1010-1015.

[30] Long, Y. J.; Li, Y. F.; Liu, Y.; Zheng, J. J.; Tang, J.; Huang, C. Z. Visual observation of the mercury-stimulated peroxidase mimetic activity of gold nanoparticles. Chem. Commun. 2011, 47, 11939-11941.

[31] Yan, L. X.; Chen, Z. P.; Zhang, Z. Y.; Qu, C. L.; Chen, L. X.; Shen, D. Z. Fluorescent sensing of mercury(II) based on formation of catalytic gold nanoparticles. Analyst 2013, 138, 4280-4283.

[32] Chen, Z. B.; Zhang, C. M.; Gao, Q. G.; Wang, G.; Tan, L. L.; Liao, Q. Colorimetric signal amplification assay for mercury ions based on the catalysis of gold amalgam. Anal. Chem. 2015, 87, 10963-10968.

[33] Han, K. N.; Choi, J. S.; Kwon, J. Gold nanozyme-based paper chip for colorimetric detection of mercury ions. Sci. Rep. 2017, 7, 2806.

[34] Wu, L. L.; Wang, L. Y.; Xie, Z. J.; Xue, F.; Peng, C. F. Colorimetric detection of $\mathrm{Hg}^{2+}$ based on inhibiting the peroxidase-like activity of DNA-Ag/Pt nanoclusters. RSC Adv. 2016, 6, 75384-75389.

[35] Yang, H. G.; Xiong, Y. H.; Zhang, P.; Su, L. J.; Ye, F. G. Colorimetric detection of mercury ions using $\mathrm{MnO}_{2}$ nanorods as enzyme mimics. Anal. Methods 2015, 7, 4596-4601.

[36] Wei, H.; Wang, E. K. Nanomaterials with enzyme-like characteristics (nanozymes): Next-generation artificial enzymes. Chem. Soc. Rev. 2013, 42, 6060-6093.

[37] Lin, Y. H.; Ren, J. S.; Qu, X. G. Nano-gold as artificial enzymes: Hidden talents. Adv. Mater. 2014, 26, 4200-4217.

[38] Gao, L. Z.; Yan, X. Y. Nanozymes: An emerging field bridging nanotechnology and biology. Sci. China Life Sci. 2016, 59, 400-402.

[39] Zhou, X. C.; Xu, W. L.; Liu, G. K.; Panda, D.; Chen, P. Size-dependent catalytic activity and dynamics of gold nanoparticles at the singlemolecule level. J. Am. Chem. Soc. 2010, 132, 138-146.

[40] Li, W.; Chen, B.; Zhang, H. X.; Sun, Y. H.; Wang, J.; Zhang, J. L.; $\mathrm{Fu}, \mathrm{Y}$. BSA-stabilized Pt nanozyme for peroxidase mimetics and its application on colorimetric detection of mercury(II) ions. Biosens.
Bioelectron. 2015, 66, 251-258.

[41] Huang, Y. Q.; Fu, S.; Wang, Y. S.; Xue, J. H.; Xiao, X. L.; Chen, S. H.; Zhou, B. Protamine-gold nanoclusters as peroxidase mimics and the selective enhancement of their activity by mercury ions for highly sensitive colorimetric assay of $\mathrm{Hg}(\mathrm{II})$. Anal. Bioanal. Chem. 2018, 410, 7385-7394.

[42] Park, K. S.; Kim, M. I.; Cho, D. Y.; Park, H. G. Label-free colorimetric detection of nucleic acids based on target-induced shielding against the peroxidase-mimicking activity of magnetic nanoparticles. Small 2011, 7, 1521-1525.

[43] Kim, H.; Lee, J. U.; Song, S.; Kim, S.; Sim, S. J. A shape-code nanoplasmonic biosensor for multiplex detection of Alzheimer's disease biomarkers. Biosens. Bioelectron. 2018, 101, 96-102.

[44] Kim, H.; Lee, J. U.; Kim, S.; Song, S.; Sim, S. J. A nanoplasmonic biosensor for ultrasensitive detection of Alzheimer's disease biomarker using a chaotropic agent. ACS Sens. 2019, 4, 595-602.

[45] Cao, C.; Sim, S. J. Preparation of highly stable oligo(ethylene glycol) derivatives-functionalized gold nanoparticles and their application in LSPR-based detection of PSA/ACT complex. J. Nanosci. Nanotechnol. 2007, 7, 3754-3757.

[46] Cao, C.; Sim, S. J. Resonant Rayleigh light scattering response of individual Au nanoparticles to antigen-antibody interaction. Lab Chip 2009, 9, 1836-1839.

[47] Cao, C.; Gontard, L. C.; Tram, L. L. T.; Wolff, A.; Bang, D. D. Dual enlargement of gold nanoparticles: From mechanism to scanometric detection of pathogenic bacteria. Small 2011, 7, 1701-1708.

[48] Haiss, W.; Thanh, N. T. K.; Aveyard, J.; Fernig, D. G. Determination of size and concentration of gold nanoparticles from UV-vis spectra. Anal. Chem. 2007, 79, 4215-4221.

[49] Gao, M.; Lyalin, A.; Taketsugu, T. Role of the support effects on the catalytic activity of gold clusters: A density functional theory study. Catalysts 2011, 1, 18-39.

[50] Wang, S.; Chen, W.; Liu, A. L.; Hong, L.; Deng, H. H.; Lin, X. H. Comparison of the peroxidase-like activity of unmodified, aminomodified, and citrate-capped gold nanoparticles. ChemPhysChem 2012, 13, 1199-1204.

[51] Lim, S. H.; Ahn, E. Y.; Park, Y. Green synthesis and catalytic activity of gold nanoparticles synthesized by Artemisia capillaris water extract. Nanoscale Res. Lett. 2016, 11, 474.

[52] Qi, G. H.; Fu, C. C.; Chen, G.; Xu, S. P.; Xu, W. Q. Highly sensitive SERS sensor for mercury ions based on the catalytic reaction of mercury ion decorated Ag nanoparticles. RSC Adv. 2015, 5, 49759-49764.

[53] Drozd, M.; Pietrzak, M.; Parzuchowski, P. G.; Malinowska, E. Pitfalls and capabilities of various hydrogen donors in evaluation of peroxidase-like activity of gold nanoparticles. Anal. Bioanal. Chem. 2016, 408, 8505-8513.

[54] Food and Drug Administration (FDA). Mercury Levels in Commercial Fish and Shellfish (1990-2012) [Online]. https://www.fda.gov/food/ foodborneillnesscontaminants/metals/ucm115644.htm. (accessed Sep 14, 2019). 